\title{
NET PRIMARY PRODUCTIVITY DYNAMICS AND DRIVING FORCES IN GUANGZHOU CITY, CHINA
}

\author{
WU, Y. ${ }^{1}-\mathrm{LUO}, \mathrm{Z}^{2}-\mathrm{WU}, \mathrm{Z}^{1 *}$ \\ ${ }^{1}$ School of Geographical Sciences/Guangdong Province Engineering Technology Research for \\ Geographical Conditions Monitoring and Comprehensive Analysis, Guangzhou University \\ 510006 Guangzhou, China
}

${ }^{2}$ South China Institute of Environmental Science, Ministry of Environmental Protection 510535 Guangzhou, China

*Corresponding author

e-mail: gzuwzf@163.com

(Received $2^{\text {nd }}$ Jul 2018; accepted $22^{\text {nd }}$ Aug 2018)

\begin{abstract}
Urban expansion and land use/land cover change (LULCC), driven primarily by human activities, have significant influences on the environment; in addition, the two factors, together with climate change, have an impact on urban vegetation. This study explored spatiotemporal dynamics of net primary productivity (NPP) and calculated relative contributions of driving factors from 2001 to 2013 in Guangzhou City, China. The effects of climate variables, urban expansion, and subsequent LULCC on interannual NPP variability were analyzed and compared. Results showed that NPP fluctuated and generally declined in Guangzhou over the 13-year study period, especially significant in inner suburbs (southern, eastern, and northern regions $(p<0.05)$, due to increasingly intensive human activities. LULCC, especially the reduction of cropland due to urban sprawl, resulted in significant NPP losses and positive relative impact index (RII) values, which indicated that LULCC played a negative role in NPP accumulation. More than $67.2 \%$ of NPP variability was controlled by LULCC in the whole area under study and mean RII values in all regions were higher than 50\%, indicating that the influence of LULCC on NPP variability was greater than that of climate change. Particularly noteworthy is the fact that local climate change had a greater influence on NPP in forested areas (e.g. in the northeastern region), but it should not be ignored that RII kept increasing annually in this region and therefore more efforts paid in conservation were required. In conclusion, urban expansion and LULCC across the whole study area are resulted from human activities, and this, rather than climate change, was the primary driving force for the regional reduction in NPP.
\end{abstract}

Keywords: net primary productivity, urban expansion, climate change, land use/land cover change (LULCC), human activities

\section{Introduction}

Net primary productivity (NPP), the amount of photosynthetically fixed carbon available to the first heterotrophic level in an ecosystem (Field et al., 1998), is a key component of energy and matter transformation in terrestrial ecosystems. NPP plays an important role in global change and carbon balance as a key regulator of ecological processes, and is often used to quantify ecosystem service values. A decline in vegetation productivity is the primary manifestation of vegetation degradation, and NPP is an important indicator of productivity. In recent years, many studies of NPP have conducted long-term monitoring of vegetation dynamics in terrestrial ecosystems on both local and global scales, and results showed that vegetated ecosystems are susceptible to the effects of climate conditions and human activities, or the combined effects of them (Fu et al., 2013; Zhang et al., 2016; $\mathrm{Wu}$ and $\mathrm{Wu}, 2018$; Chao et al., 2018; Fang et al., 2017). 
Climate change influences NPP variability by altering levels of photosynthesis, respiration, and the decomposition of organic carbon in the soil (Gong et al., 2012; Pei et al., 2013b, 2015; Wang et al., 2013). According to the study by Nemani et al. (2003), the increase in global NPP from 1982 to 1999 was partly due to global climate change, and this trend was observed in China over the same period (Piao et al., 2005). NPP variability is highly sensitive to climate change, but the mechanisms involved are complicated (Liang et al., 2014; Ahlström et al., 2012; Gu et al., 2017). Human-induced change, especially urbanization, is another important influencing factor of NPP variability with complex mechanisms (Buyantuyev and $\mathrm{Wu}, 2012$; Zhang et al., 2015; Peng et al., 2016). Growing evidence has shown that urban expansion has a great influence on regional ecosystems due to increased levels of greenhouse gas in the atmosphere, the destruction of the ozone layer, biodiversity loss due to deforestation (Verburg et al., 2002), and the reduction in landscape-level photosynthetic activity (Imhoff et al., 2000). In addition, urban expansion, together with land use/land cover (LULC) change, has dramatically influenced hydrological systems, biogeochemical cycles, and climate (Grimm et al., 2008). This has led to alterations in the distribution, structure, and material cycling of terrestrial ecosystems, ultimately affecting carbon storage and flux (Imhoff et al., 2000; Piao et al., 2009; Hutyra et al., 2011). Urbanization often causes reductions in NPP due to land cover transformation and carbon fixing potential drops greatly when the land converts from cultivated land or forests to developed land, or when a region transforms from a suburban area into an urban area (Zhao et al., 2012; Jiang and Wu, 2015; Chen et al., 2017). Therefore, climate change and human activities are two of the most important driving forces of NPP variability. With aggravating global climate change and increasing human activities, quantifying the effects of different driving factors on vegetation dynamics has become a critical issue for mitigation and management planning. To date, some studies have attempted to quantify relative contributions of climate change or human-induced LULCC to NPP within specific regions (Yan et al., 2016; Xu et al., 2011; Zhang et al., 2016). However, such studies are often lack a spatial quantitative component relating to climate change and LULCC, and they do not take the spatial differences in the impacts of these different driving forces on NPP into account.

Guangzhou City is ideal for the study of climate change and human-induced impacts on NPP because it has hot and humid subtropical monsoon climate that favors yearround vegetation growth. The city has experienced dramatic urbanization and LULCC, which have converted large patches of croplands and woodlands into built-up areas within a matter of a decade or even a few years. Guangzhou's urban development strategy of "southern expansion, northern optimization, eastern advance, western union" in its $11^{\text {th }}$ Five-year Plan will continue to accelerate urban sprawl, which may lead to multiple ecological problems. Some studies have noted that climate variables and human activities have led to a significant change in vegetation productivity in urban areas over a short period, with clear spatial heterogeneity. Accordingly, the study of NPP variability and the driving mechanisms in Guangzhou can be regarded as a representative case for southern China. This paper attempts to achieve the following goals: (1) to examine the spatiotemporal variability in NPP across five regions during 2001-2013; (2) to analyze the effects of climate variables, urban expansion, and subsequent LULCC on NPP; and (3) to reveal the relative contribution of driving forces on NPP accumulation and describe the spatial heterogeneity. 


\section{Material and methods}

\section{Study area}

Guangzhou City $\left(112^{\circ} 57^{\prime} \mathrm{E} \sim 114^{\circ} 3^{\prime} \mathrm{E}\right.$ and $\left.22^{\circ} 26^{\prime} \mathrm{N} \sim 23^{\circ} 56^{\prime} \mathrm{N}\right)$ is an important political, economic, educational, scientific, and technological center within Guangdong Province and South China (Fig. 1). It is located in the north end of the Pearl River Delta region and adjoins the extension of the Nanling Mountains in the north and the South China Sea in the south, with a total land area of $7,434.4 \mathrm{~km}^{2}$. The topography of Guangzhou consists of hilly areas and plains, with elevation decreasing from northeast to the southwest. It has a subtropical, marine monsoon climate with an annual average temperature of $22{ }^{\circ} \mathrm{C}$ and annual precipitation of $1,982.7 \mathrm{~mm}$. Guangzhou has experienced dramatic urbanization due to China's reform and opening up policies. In recent decades, Guangzhou's economy has developed fast, which supports a population of over 12.9 million. Its regional Gross Domestic Product (GDP) has grown from \$268.48 billion in 2001 to $\$ 1,542.01$ billion in 2013 (http://www.gzstats.gov.cn/). According to urban planning (Urban Master Development Plan of Guangzhou (20012010); the $10^{\text {th }}$ Five-year Plan (2001-2005) and the $11^{\text {th }}$ Five-year Plan (2006-2010)), the development of Guangzhou was predominantly in five regions, namely the central part, the south, the east, the north, and the northeast (Fig. 1). The central region mainly includes old districts with overwhelming urbanization and significant economic development. The southern, eastern, and northern regions are inner suburbs with rapid urban development. The northeastern region is composed of outer suburbs which are mainly dominated by forests and agricultural land, with relatively slower urban development.

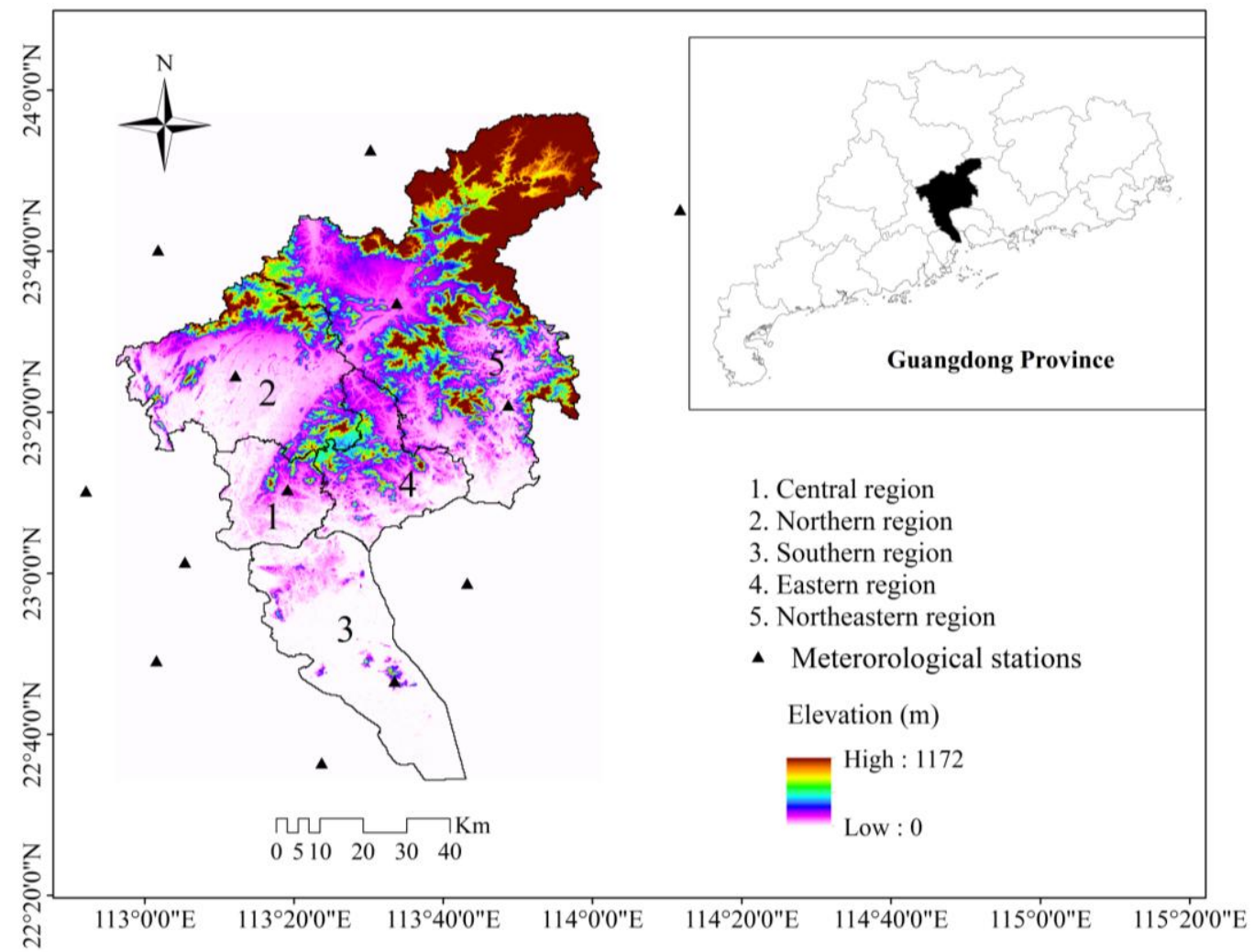

Figure 1. Location of study area, five regions and topography 


\section{Data collection and pre-processing}

In this study, Terra MODIS data over the study area from 2001 to 2013 were selected for the NPP simulation. Data included 16-day NDVI composites (MOD13Q1) at a spatial resolution of $250 \mathrm{~m}$, monthly land surface temperature (LST) (MOD11C3) at a spatial resolution of $0.05^{\circ}(5.55 \mathrm{~km})$, and monthly evapotranspiration (ET) and potential evapotranspiration (PET) (MOD16A2) at a spatial resolution of $1 \mathrm{~km}$. All MODIS datasets were downloaded from the National Aeronautics and Space Administration's (NASA) Earth Observation System. The monthly NDVI data were produced from the MODIS 16-day products by using the maximum value composites (MVC) method, which eliminated disturbances from clouds, the atmosphere, and altitude angle, and minimized non-vegetation effects (Tucker et al., 1994). Other MODIS data were aggregated to grid cells at a resolution of $250 \mathrm{~m}$ from their original Sinusoidal Projection using the MODIS Reprojection Tool (MRT) to get the same spatial resolution and projected coordinate system as the MODIS-NDVI data. All MODIS data were checked using quality flags from the companion Quality Assurance (QA) images. The MODIS LST products (MOD11C3) were used to estimate air temperature $\left(\mathrm{T}_{\text {air }}\right)$ for the CASA model. Other studies have used this method to estimate $\mathrm{T}_{\text {air }}$ from MODIS LST data, and confirmed that LST is highly correlated with $\mathrm{T}_{\text {air }}$ (Vancutsem et al., 2010; Fu et al., 2011; Benali et al., 2012). In this study, $\mathrm{T}_{\text {air }}$ was estimated using LST data based on cross validation across years (Fu et al., 2011). The results showed that the best model had $\mathrm{r}^{2}$ values ranging from 0.82 to 0.90 and RMSE values ranging from 1.64 to $2.17^{\circ} \mathrm{C}$, for $2001-2013$.

The climate data included monthly mean air temperature, total precipitation, and total solar radiation data derived from 13 meteorological stations in and around Guangzhou. These three weather variables were used to analyze the correlation with NPP and simulate $\mathrm{NPP}_{\mathrm{p}}$. and the percentage of sunlight was derived in order to calculate the total solar radiation for simulating NPPp and NPP. These climate data were then interpolated into raster format at $250 \mathrm{~m}$ spatial resolution by using the universal Kriging method to match the MODIS NDVI data. All meteorological data were downloaded from the Chinese National Metrological Information Center/China Meteorological Administration (NMIC/CMA).

Finally, a time series of Landsat images were used to extract land cover over the study areas. Data sources included Landsat Thematic Mapper (TM; bands 1-5 and 7) images acquired on November 2005, December 2006, January 2009, October 2011; Enhanced Thematic Mapper (ETM+; bands 1-5 and 7) images acquired on November 2001 and January 2003; and Operational Land Imager (OLI; bands 2-7) images acquired on December 2013. These images were rectified to the Universal Transverse Mercator (UTM) projection and World Geodetic System 1984 (WGS84) datum. After Line-of-Sight Atmospheric Analysis of Spectral Hypercube (FLAASH) and image mosaicking, the 2001 image was selected as the base image for automatic registration of other images with Root Mean Square Errors (RMSE) of less than 0.5 pixels. Subsequently, the images were masked using the boundary of the Guangzhou Metropolitan area. A maximum likelihood supervised classification approach was used to classify the Landsat images and they were combined with the actual land cover in Guangzhou and the International Geosphere-Biosphere Program (IGBP) schemes. Finally, land cover maps from seven years were classified into 12 categories (Table 1). The overall accuracy of the classification results was higher than $82.5 \%$. 
Table 1. Land use/land cover classification scheme

\begin{tabular}{c|c|c}
\hline LULC types & Description & $\varepsilon_{\max }$ \\
\hline EBF & $\begin{array}{c}\text { Lands dominated by broadleaf trees with a canopy cover great than 60\% and } \\
\text { height exceeding 2-m. Almost all trees remain green all year }\end{array}$ & 0.985 \\
\hline ENF & $\begin{array}{c}\text { Lands dominated by needleleaf trees with a canopy cover great than 60\% and } \\
\text { height exceeding 2-m. Almost all trees remain green all year }\end{array}$ & 0.389 \\
\hline MF & Lands with evergreen broadleaf and needleleaf forest & 0.475 \\
\hline DBF & $\begin{array}{c}\text { Lands dominated by broadleaf trees with a canopy cover great than 60\% and } \\
\text { height exceeding 2-m. Consists of seasonal broadleaf tree communities with an } \\
\text { annual cycle of leaf-on and leaf-off periods }\end{array}$ & 0.692 \\
\hline GL & Lands with herbaceous, tree and shrub cover is less than 10\% & 0.542 \\
\hline SL & $\begin{array}{c}\text { Lands with woody vegetation less than 2-m tall and mainly shrub and lands with } \\
\text { herbaceous types of cover, shrub cover is greater than 60\% }\end{array}$ & 0.429 \\
\hline WG & Lands with herbaceous and with tree canopy between 10 and 30\% & 0.542 \\
\hline CL & Lands covered with temporary crops followed by harvest and a bare soil period & 0.542 \\
\hline CL\&NVM & $\begin{array}{c}\text { Lands with a mosaic of croplands, forest, shrub-land, and grasslands in which no } \\
\text { one component comprises more than 60\% of the landscape }\end{array}$ & 0.542 \\
\hline WB & Oceans, seas, lakes, reservoirs, rivers and dike-pond & 0.296 \\
\hline U\&BL & Land covered by buildings and other man-made structures & 0.196 \\
\hline UL & Exposed soil, sand, rocks, landfill sites, areas of active excavation & 0.217 \\
\hline
\end{tabular}

EBF: evergreen broadleaf forests; ENF: evergreen needleleaf forests; MF: mixed forests; DBF: deciduous broadleaf forests; GL: grasslands; SL: shrub lands; WG: woody grasslands; CL: croplands; CL\&NVM: cropland/nature vegetation mosaics; U\&BL: urban and built-up lands; UL: unused lands; WB: water bodies

\section{NPP estimation}

NPP was assessed by using the Carnegie-Ames-Stanford Approach (CASA) model, a parameter-based model based on light use efficiency (Potter et al., 1993). The CASA model can be calculated as the product of the amount of photosynthetic active radiation absorbed (APAR) $\left(\mathrm{MJ} \cdot \mathrm{m}^{-2}\right)$ and the actual light use efficiency $(\varepsilon)\left(\mathrm{g} \mathrm{C} \cdot \mathrm{MJ} \cdot \mathrm{m}^{-1}\right)$ factor. NPP can be expressed as (Eq. 1):

$$
\operatorname{NPP}(x, t)=A P A R \times \varepsilon
$$

where NPP $(x, t)\left(\mathrm{g} \mathrm{C}^{-2} \mathrm{~m}^{-2}\right)$ is the net primary productivity for grid cell $x$ in month $t$. The actual light use efficiency $(\varepsilon)$ is affected by temperature and water, and can be calculated by using Equation 2:

$$
\varepsilon(x, t)=T_{1}(x, t) \times T_{2}(x, t) \times W(x, t) \times \varepsilon_{\max }
$$

where $T_{1}(x, t)$ and $T_{2}(x, t)$ are temperature stress coefficients; $W(x, t)$ is a moisture stress coefficient; and $\varepsilon_{\max }$ represents the maximum light use efficiency that needs to be simulated for different vegetation types. $\varepsilon_{\max }$ differs greatly in different situations and is mainly affected by temperature, water availability, soil type, etc. (Prince, 1991). In this paper, the $\varepsilon_{\max }$ values for different land cover types were adopted from Zhu et al. (2006) who computed $\varepsilon_{\max }$ according to the principle of minimal error based on simulated NPP and measured ground NPP. 
$A P A R$ is the product of $P A R$ and the fraction of photosynthetically active radiation (FPAR) (Wang et al., 2009), and PAR depends on the solar surface radiation (SOL) $\left(\mathrm{MJ} \cdot \mathrm{m}^{-2}\right)$. Thus, NPP at location $x$ and time $t$ becomes $(E q .3)$ :

$$
N P P(x, t)=F P A R \times S O L \times 0.5 \times T_{1}(x, t) \times T_{2}(x, t) \times W(x, t) \times \varepsilon_{\max }
$$

FPAR is defined as a linear function of $N D V I$ and the simple ratio $(S R)(E q .4)$ :

$$
F P A R(x, t)=\alpha \text { FPAR }_{\text {NDVI }}+(1-\omega) \text { FPAR }_{S R} \quad \text { FPAR } \in[0.001,0.95]
$$

where $\alpha$ is set to $0.5 ; F P A R_{\mathrm{NDVI}}$ and $F P A R_{\mathrm{SR}}$ are FPAR estimated by the NDVI-FPAR model (Eq. 5) and the SR-FPAR model (Eq. 6):

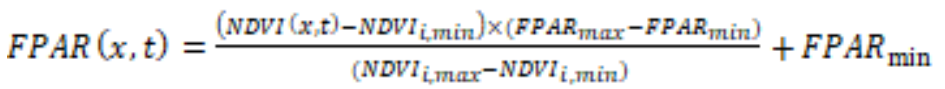

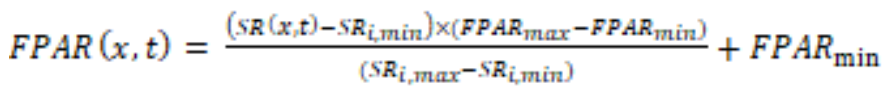

where $N D V I_{i, \max }$ and $N D V I_{i, \min }$ values correspond to $95 \%$ and $5 \%$ of the $N D V I$ population respectively, and $i ; S R_{i, \max }$ and $S R_{i, \min }$ correspond to $N D V I_{i, \max }$ and $N D V I_{i, \min }$ respectively. The relationship between $N D V I$ and $S R$ can therefore be expressed as (Eq. 7):

$$
\operatorname{SR}(x, t)=\left[\frac{1+\text { NDVITx:t })}{1-\text { NDVI[x,t } t)}\right]
$$

$S O L$ is the total solar radiation over time period $\left(M J \cdot m^{-2}\right)$, can be calculated based on the percentage of sunshine, namely $(E q .8-12)$ :

$$
\begin{gathered}
S O L=\left[a+b \times \frac{n}{N}\right] \times R_{a} \\
R_{a}=S_{0} \times \frac{24}{\pi} \times d \times\left(W_{0} \times \sin \varphi \times \sin \delta+\cos \varphi \times \cos \delta \times \sin W_{0}\right) \\
d=1 /[1+0.033 \times \cos (2 \pi \times J / 365)] \\
\delta=0.409 \times \sin (2 \pi \times] / 365-1.39) \\
W_{0}=\operatorname{arcos}(-\tan \varphi \times \tan \delta)
\end{gathered}
$$

where $R_{a}$ is the vertical incidence of solar radiation from the upper atmosphere; $n / N$ is the percentage of sunshine; $a$ and $b$ are set to 0.191 and 0.758 , respectively, according to Hou et al. (1993); $S_{0}$ is a solar constant $\left(0.082 \mathrm{MJ} \cdot \mathrm{m}^{-2} \cdot \mathrm{min}^{-1}\right)$; $d$ is a correction factor for the relative distance between Earth and the Sun; $\delta$ is solar declination (unit: radians); 
$W_{0}$ is the hour angle between sunrise and sunset (unit: radian); $\varphi$ is geographic latitude (unit: radians), and is set to 0.540 ; and $J$ is the number of days in a year.

Additionally, $T_{1}(x, t), T_{2}(x, t)$ and $W(x, t)$ are the temperature and moisture stress coefficients, and can be calculated as (Eq. 13-15):

$$
\begin{gathered}
T_{1}(x, t)=0.8+0.02 \times T_{\text {opt }}-0.0005 \times\left(T_{o p t}\right)^{2} \\
T_{2}(x, t)=1.184 /\left[1+e^{0.2 *\left[T_{w p t}-10-T[x]\right)}\right] /\left[1+e^{0.3 *\left[-T_{o p t}-10+T[x)\right]}\right] \\
W(x, t)=0.5+0.5 \times E T(x, t) / P E T(x, t)
\end{gathered}
$$

where $T_{\text {opt }}$ is the temperature at which $N D V I$ reaches its maximum for the whole year, and $T_{2}$ falls to half its value at $T_{\text {opt }}$ at temperatures $10{ }^{\circ} \mathrm{C}$ or $13{ }^{\circ} \mathrm{C}$ below $T_{\text {opt }}$. The moisture stress coefficient $(W)$ reflects the influence of the effective water condition of plants and can be used for light utilization. It is determined by regional actual evapotranspiration $(E T)(\mathrm{mm})$ and potential evapotranspiration $(P E T)(\mathrm{mm})$, derived from the MOD16A2 products.

\section{Mann-Kendall trend analysis and Theil-Sen median slope estimator}

In the present study, both spatial and temporal NPP change trends were analyzed using a robust non-parametric Mann-Kendall (M-K) method, which is widely applied to long-time series trend analysis of non-normal data (Prince, 1991; Wang et al., 2001, $2015 b)$. It has been reported that the $M-K$ test statistic $Z$ is approximately normally distributed with the sample size $n \geq 8$ (Neeti and Eastman, 2011). A positive or a negative of $Z$ value indicates an increasing or a decreasing trend, which is monotonic (Neeti and Eastman, 2011). The M-K test statistic $S$ is calculated as (Eq. 16; Kendall, 1975):

$$
S=\sum_{i=1}^{n-1} \sum_{j=i+1}^{n} \operatorname{sgn}\left(x_{j}-x_{i}\right)
$$

where $n$ is the number of data points; $x_{i}$ and $x_{j}$ are the data values in time series $i$ and $j$ $(j>i)$, respectively; and $\operatorname{sgn}\left(x_{j}-x_{i}\right)$ is the sine function expressed as (Eq. 17):

$$
\operatorname{sgn}\left(x_{j}-x_{i}\right)=\left\{\begin{array}{c}
1, \text { if } x_{j}-x_{i}>0 \\
0, \text { if } x_{j}-x_{i}=0 \\
-1, \text { if } x_{j}-x_{i}<0
\end{array}\right.
$$

The variance is computed as (Eq. 18):

$$
\operatorname{Var}(S)=\frac{n[n-1)(2 n+5)-\sum_{i=1}^{n} t_{i}\left(t_{i}-1\right)\left(2 t_{i}+5\right)}{18}
$$

where $n$ is the number of data points, $m$ is the number of tied groups, and $t_{i}$ denotes the number of ties with extent $i$. A tied group is a set of sample data that share the same value. In cases where the sample size $\mathrm{n}>8$, the standard normal test statistic $Z_{S}$ is calculated (Eq. 19) using Equation 18: 


$$
Z= \begin{cases}\frac{s-1}{\sqrt{\operatorname{Var}[S]}}, & \text { if } S>0 \\ 0, & \text { if } S=0 \\ \frac{s+1}{\sqrt{\operatorname{Var}[S]}}, & \text { if } S<0\end{cases}
$$

In this study, the $\mathrm{Z}$ score thresholds used for testing significance over time were 1.96 for the 5\% significant level $(\propto=0.05)$, and 2.576 for the $1 \%$ significant level $(\propto=0.01)$, which provided both the significance and direction of the trend.

The Theil-Sen median slope estimator for estimating the slope of the trend in a sample with $\mathrm{N}$ pairs of data, which is appropriate for assessing the rate of change in a short or noisy time series (Wang et al., 2015a), can be calculated as (Eq. 20):

$$
\beta_{i}=\operatorname{Median}\left(\frac{x_{j}-x_{k}}{j-k}\right) \quad \text { for } i=1, \ldots, N
$$

where $x_{j}$ and $x_{k}$ are the data values at times $j$ and $k(j>k)$, respectively.

All analyses were conducted using ENVI 5.1 (Exelis Visual Information Solutions, Boulder, CO, USA), ARCGIS 10.2 (ESRI, Redlands, CA, USA), and MATLAB R2014a (The Mathworks, Inc., Natick, MA, USA).

\section{Impacts assessment of LULCC on NPP}

Based on the relative impact index (RII) from Wu et al. (2018), we applied RII to assess the impact of LULCC driven by human activities on NPP. RII was calculated based on $N P P_{\text {lulcc }}$ and $N P P_{p}$, namely (Eq. 21):

$$
R I I=\frac{N P P_{\text {luler }}}{N P P_{p}} \times 100 \%=\frac{\mathbb{N P P _ { p }}-\mathbb{N P P _ { \text { luler } }}}{\mathbb{N} P P_{p}} \times 100 \%
$$

where $N P P_{\text {lulc }}$ is the NPP variability that is due to LULCC driven by human activities, and $N P P_{p}$ is the NPP of potential vegetation. If $R I I>0$, it implies that there is a negative impact of LULCC on NPP and vegetation activity, and if $R I I<0$, it implies that there is either a limited human impact or more effective vegetation protection and management. When $|R I I|>50 \%$, it indicates that LULCC is the primary driver of NPP change. For more details about $R I I$ and the calculation of $N P P_{\mathrm{p}}$ see $\mathrm{Wu}$ et al. (2018).

\section{Relative contributions of climate and LULCC on NPP}

The correlation between climatic variables (temperature, precipitation and solar radiation) and annual NPP can be expressed as (Eq. 22):

$$
R_{x y}=\frac{\sum_{i=1}^{M}\left[\left(x_{i}-\bar{x}\right)\left(y_{i}-\bar{y}\right)\right]}{\sqrt{\sum_{i=1}^{M}\left[\left(x_{i}-\bar{x}\right)^{2} x \sum_{i=1}^{M}\left(y_{i}-\bar{y}\right)^{2}\right.}}
$$

where $R_{x y}$ is the correlation coefficients between $x$ and $y, x_{i}$ and $y_{i}$ is the value of NPP and climatic variables in the $i$ th year respectively; $\bar{x}$ and $\bar{y}$ is the mean value of NPP and climatic variables from 2001 to 2013. 
The method of Wu et al. (2014) was employed to compare the comprehensive impact of climate change and LULCC on NPP on a spatial scale, using the variation slope of NPP in different situations to quantify and compare the comprehensive impacts. Assuming that the slope of NPP was $K_{1}$ and $K_{2}$ in the situation of constant climate and constant LULCC respectively, the slope of actual NPP was $K$, so the impact of climate change and LULCC on NPP can be expressed as $\triangle C l i . N P P=K-K_{1}$ and $\triangle L U L C C . N P P=K-K_{2}$ respectively. The impact of other factors on NPP was $\triangle$ Inter.NPP $=\left(K_{1}+K_{2}\right)-K$. Therefore, the contributions of climate change, LULCC and other factors on NPP change can be described by Equations 23-25:

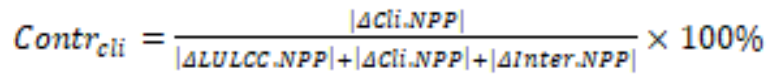

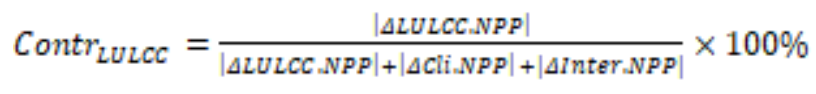

$$
\begin{aligned}
& \text { Contr }_{\text {inter }}=100-\text { Contr }_{\text {eli }}-\text { Contr }_{\text {LULCe }}
\end{aligned}
$$

The sum of the contributions of climate change, LULCC and other factors on NPP change is equal to 1 . The contributions of the three impact factors can be mapped individually at the pixel scale, and the synthesized impact image can be derived from the three images using a Maxwell Triangle.

\section{Results}

\section{NPP model validation}

There was little field data on NPP available for validating the CASA model outputs. We compared our simulated average annual NPP values over the period from 2001 to 2013 with MOD17A3 NPP values and other domestic simulation results. As shown in Figure 2, there was a strong agreement between our simulated NPP results and MOD17A3 NPP values with a correlation coefficient of 0.860 and a mean relative error of $24.88 \%$ across the 118 random sample points. The NPP values from our simulation results were clearly different from those of other studies (Table 2), which may have been due to differences in the study range, stand age and density, hydrothermal conditions, vegetation coverage, input data sources, parameter values for the CASA model, and so on.

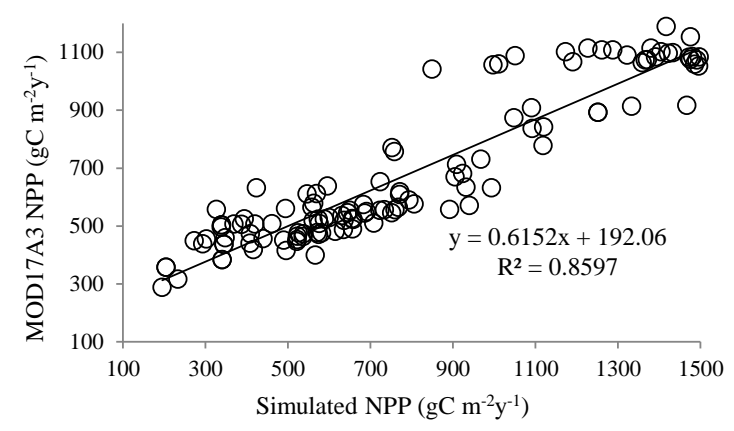

Figure 2. Correlation between simulated NPP values and MOD17A3 NPP values 
Table 2 Comparison of the mean annual NPP $\left(g C \cdot m^{-2}\right)$ for different land covers and other model output or datasets

\begin{tabular}{c|c|c|c|c|c|c|c}
\hline $\begin{array}{c}\text { Land cover } \\
\text { types* }\end{array}$ & $\begin{array}{c}\text { This } \\
\text { study }\end{array}$ & $\begin{array}{c}\text { Ni et al., } \\
\mathbf{2 0 0 3}\end{array}$ & $\begin{array}{c}\text { Zhu et al., } \\
\mathbf{2 0 0 7 b}\end{array}$ & $\begin{array}{c}\text { Gao et al., } \\
\mathbf{2 0 0 8}\end{array}$ & $\begin{array}{c}\text { Jiang et al., } \\
\mathbf{2 0 1 5}\end{array}$ & Hua, 2009 & MOD17A3 \\
\hline EBF & $1,327.22$ & 1016.5 & 985.8 & 718.0 & 833.06 & $1,046.89$ & 913.93 \\
ENF & 515.69 & 395.5 & 367.1 & 358.0 & 519.34 & 799.53 & 388.0 \\
MF & 595.68 & - & 347.1 & 707.0 & 533.49 & 874.36 & 456.0 \\
DBF & 827.43 & 671.8 & 642.9 & 472.0 & 744.7 & 818.28 & 622.02 \\
GL & 582.00 & 230.6 & 382.8 & 208.0 & 470.04 & 384.4 & 317.0 \\
SL & 483.08 & 364.2 & 367.7 & 700.0 & 524.25 & 603.94 & 415.0 \\
WG & 634.63 & - & 465.0 & - & - & 657.13 & 398.32 \\
CL & 644.06 & 532.9 & 426.5 & 577.0 & 534.74 & 416.9 & 609.91 \\
CL\&NVM & 661.62 & - & - & - & - & - & 566.02 \\
WB & 250.48 & - & - & - & 395.18 & - & - \\
U\&BL & 183.39 & - & - & - & 384.04 & - & - \\
UL & 239.47 & - & - & - & 514.47 & - & - \\
\hline
\end{tabular}

The full names of the land types match those in Table 1

\section{Spatial-temporal dynamics of NPP}

The estimated mean NPP had an overall decreasing trend from 2001 to 2013 in Guangzhou (from $807.45 \mathrm{gC} \mathrm{m}^{-2}$ in 2001 to $719.84 \mathrm{gC} \mathrm{m}^{-2}$ in 2013). From a geographical perspective, the average mean NPP decreased markedly from the northeast to the south and had clear geographic heterogeneity (Fig. 3a).
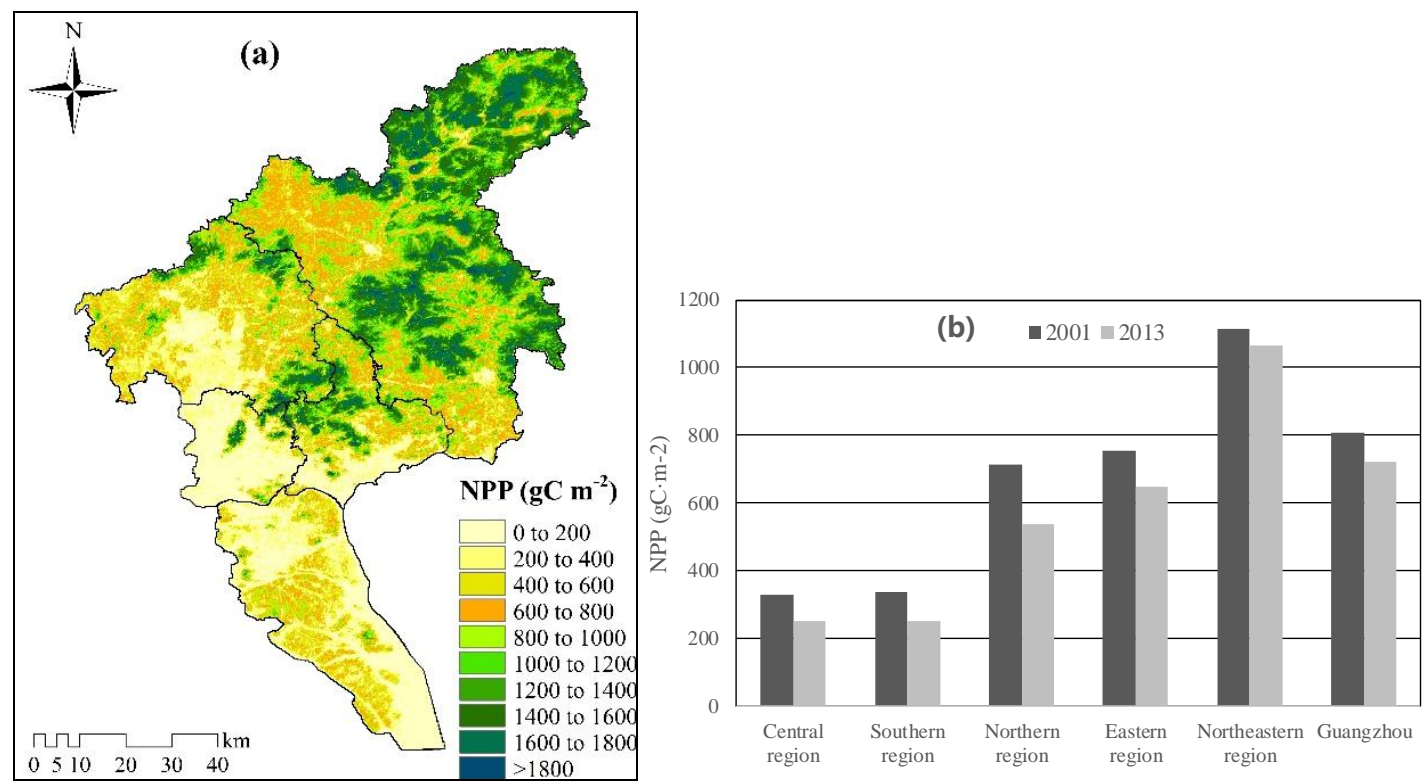

Figure 3. Spatial pattern of mean NPP during 2001-2013 (a) and NPP variability between 2001 and 2013 in Guangzhou (b)

For individual grid cells, the annual mean NPP values ranged from $7 \mathrm{gC} \mathrm{m}^{-2} \mathrm{yr}^{-1}$ in the central region to more than $1189 \mathrm{gC} \mathrm{m}^{-2} \mathrm{yr}^{-1}$ in the northeastern region. For different 
land cover types, the highest NPP values (greater than $850 \mathrm{gC} \mathrm{m}^{-2}$ ) were found in forests, which are mainly located in the northeast and the important conservation areas within Guangzhou city. Low NPP values (less than $250 \mathrm{gC} \mathrm{m}^{-2}$ ) were found in the areas dominated by urban land cover with little green space, implying that NPP was closely related to NDVI and the light use efficiency $(\varepsilon)$ of the land cover type. Fig. $3 b$ details the changed in NPP from 2001 to 2013 in Guangzhou city and the five regions. Average NPP values across Guangzhou and the five regions between 2001 and 2013 varied significantly and declined sharply by 2013. Estimated NPP values in the northern region decreased the most $\left(175.47 \mathrm{gC} \mathrm{m}^{-2}\right)$, followed by the eastern and southern regions (108.26 $\mathrm{gC} \mathrm{m}^{-2}$ and $86.52 \mathrm{gC} \mathrm{m}^{-2}$ respectively). Values in the northern region also decreased, and the lowest value was $46.90 \mathrm{gC} \mathrm{m}^{-2}$. The pattern overall showed that the order of dynamic changes in annual NPP ranked from high to low was inner suburbs, inner city, and outer suburbs.

To further assess the temporal changes and regional disparity in NPP under changing land cover, land types in Guangzhou city and the five regions were analyzed for 2001, 2005, 2009, and 2013. The results showed that the mean NPP of land cover classes in those regions varied significantly (Fig. 4). The lowest NPP values for all land cover types were found in the central region, while land cover in the northeastern region contained more NPP with more than $3,000 \mathrm{gC} \mathrm{m}^{-2}$ in all year. The average NPP for all land cover types decreased across the whole study area and all regions, with the most significant decreases occurring in the northern region with a remarkable decline of $183.78 \mathrm{gC} \mathrm{m}^{-2}$ between 2001 and 2013, followed by the southern and eastern regions with respective losses of $-72.73 \mathrm{gC} \mathrm{m}^{-2}$ and $-64.95 \mathrm{gC} \mathrm{m}^{-2}$, respectively.
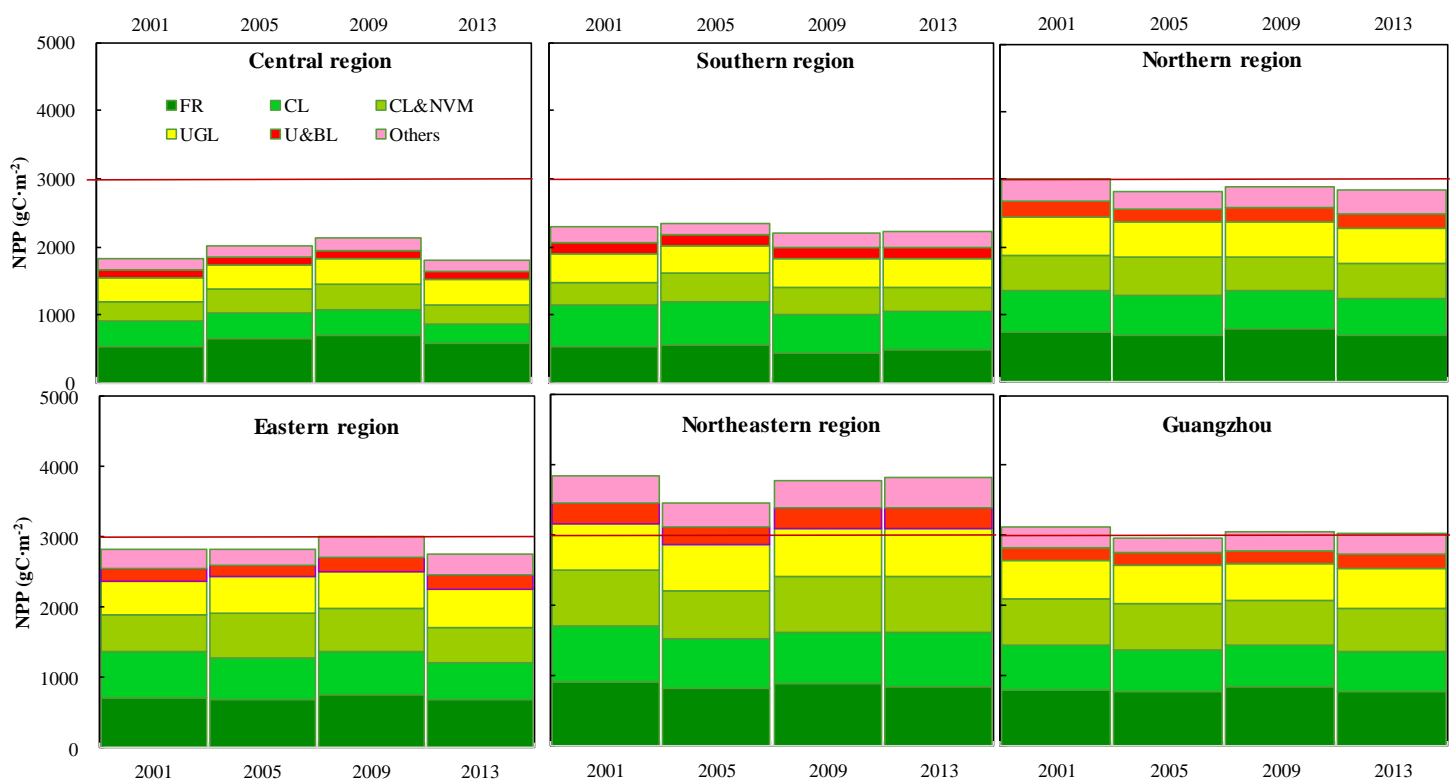

Figure 4. Changes in the mean NPP across Guangzhou City and its five regions. (FR: forest;

CL: croplands; CL\&NVM: cropland/nature vegetation mosaics; UGL: urban green lands: mainly includes grasslands: shrub lands and woody lands; U\&BL: urban and built-up lands; Others: include water bodies and unused lands)

Spatial NPP trends and tests for significance across Guangzhou and the five regions were analyzed at the pixel level (Fig. 5a-b). Results showed that NPP decreased in all 
regions over the duration of the study (slope $<0$ ). About $70.2 \%$ of all NPP pixels had a decreasing trend with an average slope of -10.94 , and this was especially noticeable in the central part of the northern region and most areas of the southern region. Pixels with a significant decreasing trend $(p<0.05)$ accounted for $19.34 \%$ of the total pixels, and only $3.44 \%$ of pixels had a significantly increasing trend $(p<0.05)$. Significant negative trends $(p<0.05)$ were mainly observed in the northeastern region $(7.75 \%)$ and in portions of the northern region $(5.34 \%)$. Of all pixels with significant positive trends ( $p<0.05$ ), about $61.01 \%$ were concentrated in the forested lands of northeastern region due to relatively less human interference and policy protection measures (e.g., Land Use Master Plan of Guangzhou, 1997-2010); however, the increasing number of pixels with a declining trend in this region cannot be ignored. Moreover, in the five regions where human modifications of land cover occurred the most, the proportion of areas with significant NPP decreases was much higher than the area of increase.
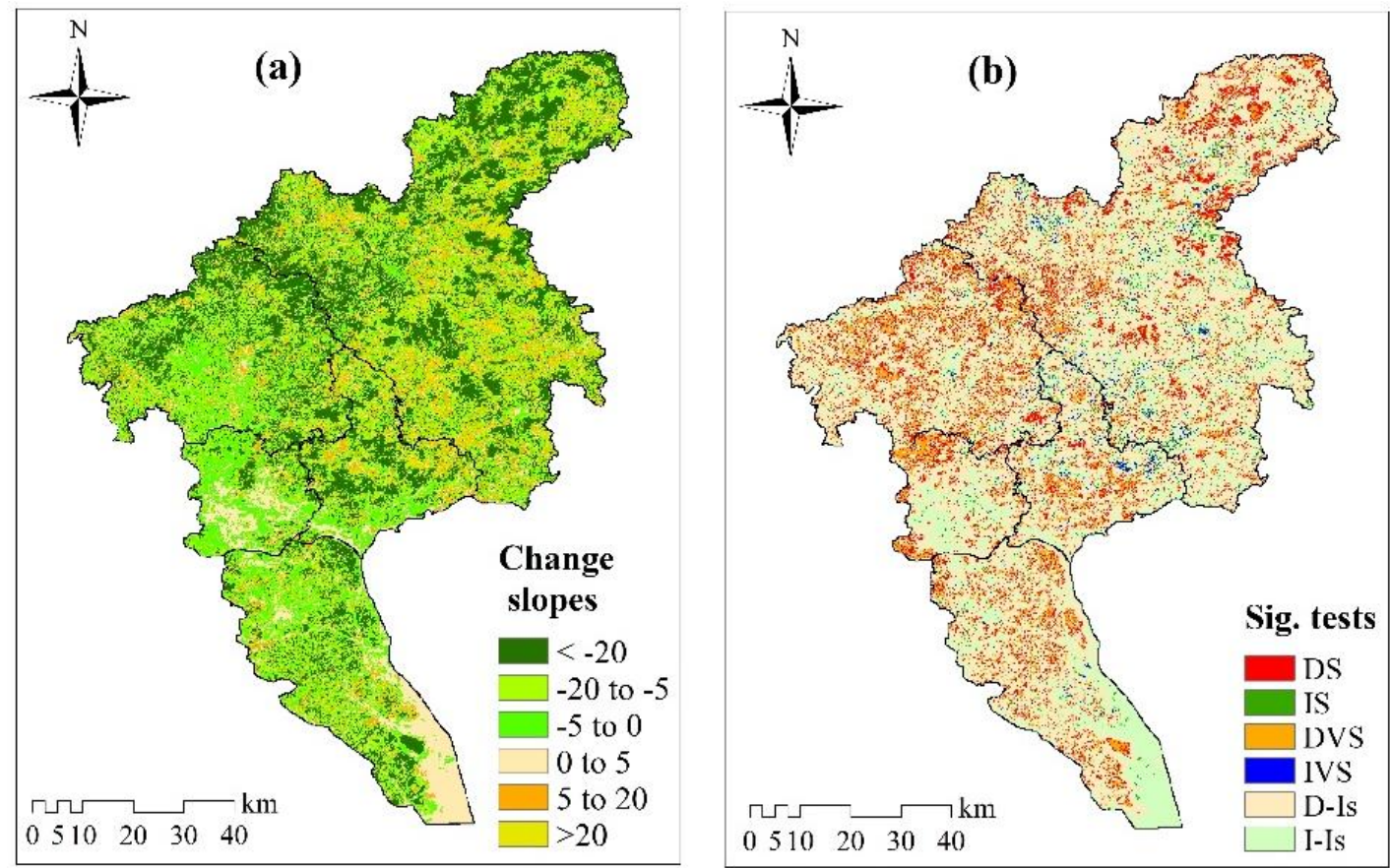

Figure 5. Change trends (a) and significance tests for NPP (b) from 2001 to 2013. (DS: decreased significantly; IS: increased significantly; DVS: decreased very significantly; IVS: increased very significantly; D-Is: decreased insignificantly; I-Is: increased insignificantly)

\section{The influence of climate variability on NPP}

Correlation analysis was performed between each climate factor (annual mean temperature (TEM), total precipitation (PRE), and total solar radiation (SOL)) and annual mean NPP across Guangzhou City and the five regions from 2001-2013 (Table 3). At the 13-year time scale, temperature and solar radiation tended to have positive impacts on NPP over the entire region, while precipitation had a negative relationship that was especially significant in the eastern and northeastern regions. The results indicated that rising temperatures and increasing solar radiation were associated with NPP increases, and solar radiation had a greater effect on NPP than temperature did. 
Table 3. Correlation coefficients between climate variables and NPP

\begin{tabular}{c|c|c|c|c|c|c}
\hline Correlation & $\begin{array}{c}\text { Central } \\
\text { region }\end{array}$ & $\begin{array}{c}\text { Southern } \\
\text { region }\end{array}$ & $\begin{array}{c}\text { Northern } \\
\text { region }\end{array}$ & $\begin{array}{c}\text { Eastern } \\
\text { region }\end{array}$ & $\begin{array}{c}\text { Northeastern } \\
\text { region }\end{array}$ & $\begin{array}{c}\text { Guang } \\
\text { zhou }\end{array}$ \\
\hline $\mathrm{R}_{\mathrm{NPP}-\mathrm{T}}$ & 0.530 & 0.394 & 0.512 & 0.351 & 0.444 & 0.476 \\
$\mathrm{R}_{\mathrm{NPP}-\mathrm{P}}$ & -0.301 & -0.217 & -0.166 & $-0.582^{*}$ & $-0.645^{*}$ & $-0.572^{*}$ \\
$\mathrm{R}_{\mathrm{NPP}-\mathrm{SOL}}$ & $0.654^{*}$ & 0.440 & $0.644^{*}$ & $0.661^{*}$ & $0.779^{* *}$ & 0.304 \\
\hline
\end{tabular}

$\mathrm{R}_{\mathrm{NPP}-\mathrm{T}}, \mathrm{R}_{\mathrm{NPP}-\mathrm{P}}$ and $\mathrm{R}_{\mathrm{NPP}-\mathrm{SOL}}$ are the correlations between NPP and temperature, precipitation and solar radiation, respectively

For further analyzed the influence of each climatic factor (TEM, PRE, SOL) on NPP dynamics, the proportion of areas whose NPP variability was influenced by climate variables were calculated, and those percentages are shown in Figure 6. Across the whole study area, the area proportion dominated by solar radiation variation was the largest, being $37.9 \%$, followed by temperature. For the five regions, solar radiation was the most dominant; particularly, the figures in the northern and northeastern regions reached $42.3 \%$ and $40.3 \%$, respectively, while the figures in the areas dominated by precipitation were always smaller (less than 30\%). These results suggested that the variability in solar radiation in the study area had the greatest influence on NPP, followed by temperature. Furthermore, changes in solar radiation and temperature strongly affected NPP in most areas of Guangzhou, while precipitation was a limiting factor for NPP accumulation due to the regional rainy and humid climate characteristics.

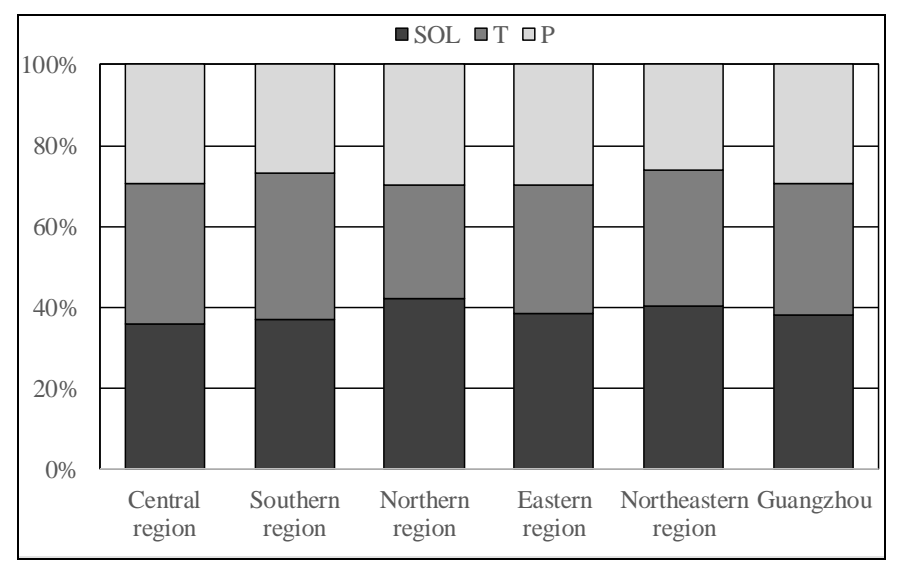

Figure 6. Pixels percentages dominated by climate variables

\section{The response of NPP to $L U L C C$}

Since 1978, Guangzhou has experienced rapid urbanization and industrialization. A trend of sustained and accelerating development has taken place from 2001 to 2013 (Wu et al., 2016), and there was considerable change in land use types during this period. For example, urban and built-up areas increased by $979.72 \mathrm{~km}^{2}$ at an annual rate of $8.13 \%$. This was especially pronounced in the southern and eastern regions, where urban land increased by more than $20.0 \%$ as cropland decreased significantly in both (Table 4). In addition, there was a significant conversion from cropland, forest, and cropland/natural vegetation patches to impervious surface. In most cases, this resulted in significant losses of NPP. 
Results showed that about $0.59 \mathrm{Tg} \mathrm{C}$ of NPP was lost due to the transformation from vegetated to non-vegetated areas between 2001 and 2013, and $85.1 \%$ of that was due to the conversion to urban land. In the five regions, the most significant losses in total NPP due to the conversion from other land cover types to urban land occurred in the northeastern region (a $42.5 \%$ loss), followed by the eastern region (18.6\%) and northern region (17.9\%). The greatest NPP losses due to conversion to other land cover types, especially urban land, occurred in cropland. This process reduced the carbon sequestration capacity of Guangzhou City. To further illustrate the impacts of urban expansion and cropland reduction on NPP loss, NPP changes in the urban and built-up coverage in 2013 and in the cropland coverage in 2001 during 2001-2013 were analyzed and compared (Fig. 7). Results showed that within the coverage of urban and built-up of 2013, urban and built-up areas had increased by $1,133.82 \mathrm{~km}^{2}$ from 2001 to 2013 , resulting a significant NPP loss of $0.55 \mathrm{Tg} \mathrm{C}$ of NPP with a decreased rate of $15.73 \mathrm{gC} \mathrm{m}^{-2} \mathrm{yr}^{-1}$ due to the conversion from vegetation to built-up areas over the 13year period, especially from cropland to construction lands. Based on the cropland coverage of 2001, cropland declined sharply by $746.75 \mathrm{~km}^{2}$ from 2001 to 2013 , and about $320.93 \mathrm{~km}^{2}$ was swallowed up by urban expansion, this directly led to the decline of the carbon fixation capacity of vegetation. During the 13-year period, NPP decreased significantly with a loss of $0.40 \mathrm{Tg} \mathrm{C}$, and about $0.19 \mathrm{Tg} \mathrm{C}$ loss was mainly ascribed to the conversion from cropland to impervious surface. The above analysis showed that in both coverages, NPP decreased very significantly from 2001 to 2013 due to gradually reducing vegetation coverage and increasing built-up lands caused by anthropogenic influence.
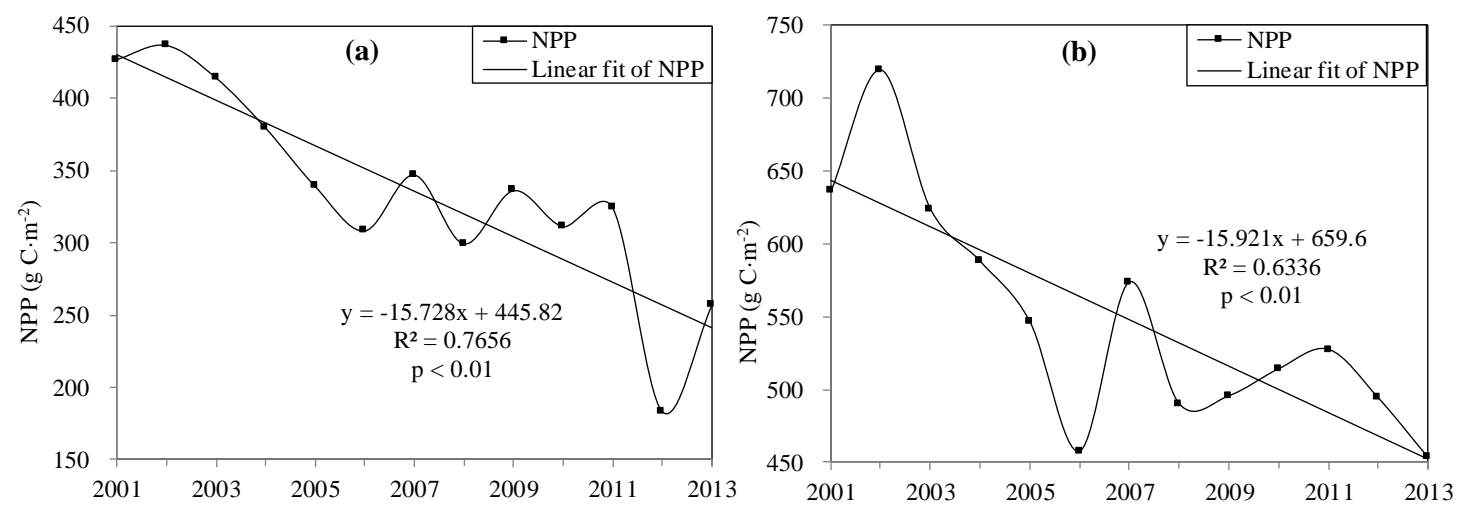

Figure 7. NPP changes from 2001 to 2013 based on the range of urban and built-up lands in 2013 (a) and cropland in 2001 (b)

Table 4. Change in three indices in the five regions from 2001 to 2013

\begin{tabular}{|c|c|c|c|c|c|}
\hline Indices & Central region & Southern region & $\begin{array}{l}\text { Northern } \\
\text { region }\end{array}$ & Eastern region & $\begin{array}{l}\text { Northeastern } \\
\text { region }\end{array}$ \\
\hline$\Delta \mathrm{U} \& \mathrm{BL}(\%)$ & 19.84 & 20.73 & 15.85 & 22.16 & 6.48 \\
\hline$\Delta \mathrm{CL}(\%)$ & -9.81 & -14.36 & -6.51 & -12.23 & -4.90 \\
\hline$\Delta \mathrm{RII}(\%)$ & 4.62 & 6.52 & 9.19 & 7.27 & 5.98 \\
\hline
\end{tabular}

$\triangle \mathrm{U} \& B L$ and $\triangle \mathrm{CL}$ is the proportion of urban area and cropland change respectively; $\Delta \mathrm{RII}$ is the difference in RII between 2013 and the 13-year average 
The impacts of LULCC on NPP were further investigated by examining the RII over the whole study area and the five regions from 2001 to 2013. Results showed that more than $91.0 \%$ of pixels in whole area had positive RII values and the mean RII value was greater than $50 \%$ across all regions, indicating LULCC driven by human activity had a negative influence on NPP and was the primary cause for NPP losses. Moreover, there was a clear increasing trend in RII across the five regions over the 13 years (Table 4) that was especially significant in the northern region followed by the eastern and southern regions, which suggested that intense human development radiated outward from the central urban areas to the urban fringe, where the inner suburbs were the first to be affected.

\section{Comparison of the effects of LULC and climate change on NPP}

In this study, we measured the relative contributions and synthesized the spatial impacts of climate and LULCC on NPP (Fig. 8a). The results showed that there were significant differences between the major factors controlling NPP at the pixel level. Over 13 years in the study area, $67.2 \%$ of all pixels had NPP variability that was dominated by LULCC due to increased human activities (Fig. 8b).

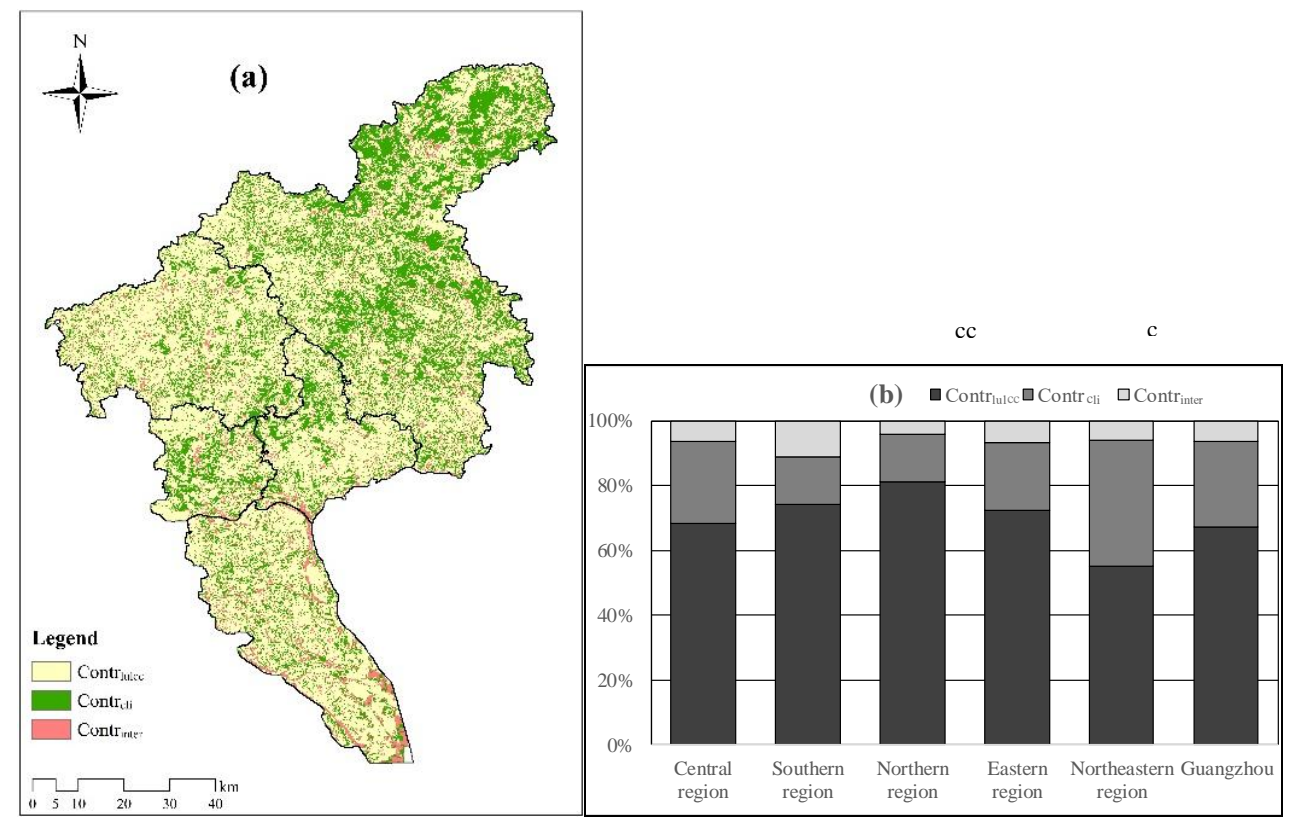

Figure 8. Spatial distribution (a) and percentages (b) of the relative contributions of climate

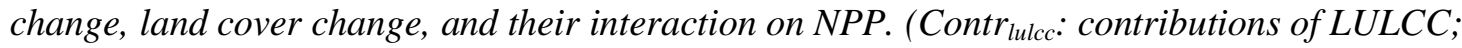
Contr ${ }_{\text {cli }}$ : contributions of climate change; Contr ${ }_{\text {inter }}$ : contributions of the interaction effects)

These were mainly distributed in the northern, eastern, and southern regions, indicating that LULCC had a negative influence on NPP. On the other hand, $26.6 \%$ of pixels with NPP variability were more sensitive to climate change and mainly concentrated in the northeastern region dominated by forested lands. Only $6.2 \%$ of the total pixels were controlled by the interaction of climate and LULCC, and they were mainly concentrated in central region and some areas of southern region. Moreover, the proportion of pixels whose NPP changes were controlled by LULCC was higher than $50.0 \%$ across all regions, indicating that LULCC dominated by human activities and had a greater 
influence on NPP variability than climate change, especially in the inner suburbs (about $76.66 \%$ of pixels with NPP variability were controlled by LULCC). Overall, results showed that the influence of urban expansion and LULCC on NPP was much greater than the influence of climate, and LULCC was the main cause of reduced NPP in most of the areas under study.

\section{Discussion}

\section{Uncertainties in NPP estimates}

Compared with MODIS NPP, we found that our simulated NPP values for all land cover types were higher than MOD17A3, which may be because the fact that MODIS NPP is derived at the global scale with diverse climate and vegetation conditions and at a relatively coarse spatial resolution $(1 \mathrm{~km})$. The NPP estimates in this study were also very different from previous research studies of NPP change during China's urbanization (Table 2), which may be due to the fact that Guangzhou is a southern city with a warmer climate, higher vegetation coverage, and better hydrothermal conditions than that of other cities and the whole country.

In addition, there could be large uncertainties in this NPP estimation due to input data, parameters, model structure, and the applicability of the model ( $\mathrm{Wu}$ and $\mathrm{Wu}$, 2018). Some parameters (e.g., $\varepsilon_{\max }$ and FPAR) in the CASA model may not be appropriate across all areas of China and the process parameters should be optimized (Wang et al., 2013; Gong et al., 2012; Zhang et al., 2009). Furthermore, there was a large disparity in the spatial resolution of meteorological data and MODIS products in this study, which may have caused bias in NPP estimation. Although we reduced these errors by resampling, further adjustment and higher resolution data may be needed. Additionally, ground NPP data-based site observations of biomass within the study would have been better for validation than MODIS NPP. Overall, there were still some uncertainties in the NPP estimates due to the factors mentioned above, and in future studies, optimization of model parameters and more multisource data validation will be needed to enhance the accuracy of NPP estimation.

\section{Correlation between climate variability and NPP}

Climate variables are important factors affecting vegetation conditions, for example, temperature, precipitation and solar radiation can affect the vegetation distribution and NPP dynamics of various biomes at regional, and even local, scales (Dekker et al., 2007; Hu et al., 2009; Zhu et al., 2007a). In this study, the effects of these three climate variables on NPP variability were different, however, negative correlations with NPP and precipitation, and positive correlations with NPP and temperature and solar radiation occurred in all regions (Table 3), indicating that precipitation was unfavorable for vegetation growth, while temperature and solar radiation benefited NPP accumulation. This was consistent with Fu et al.'s (2013) study on Guangzhou where an increase in precipitation caused a decrease in temperature and radiation, which reduced the solar radiation exposure and for photosynthesis for photosynthesis in plants and may have decreased the soil organic matter content (Mohamed et al., 2004; Eisfelder et al., 2014; Zhang et al., 2016), resulting in less absorption of photosynthetically active radiation and the accumulation of vegetation biomass (Piao et al., 2003). 
Solar radiation serves as an important energy source for plant photosynthesis, and we found it had a better regression coefficient with NPP than temperature and precipitation across all regions (Table 3). This implied that the NPP distribution and production are closely related to climatic variables and always dominated by a single climatic factor (Zhao and Running, 2010; Wu et al., 2014), and in most areas of Guangzhou City, the response of interannual NPP variability to solar radiation was the main controlling factor (Fig. 6). The results also have been verified by other studies (Zhang et al., 2014; Liang et al., 2014). Moreover, according to Zhu et al. (2007a), solar radiation had a larger influence on vegetation NPP in the South China compared with temperature and precipitation. Although other environmental factors may also affect NPP variability to some extent, such as soil texture (Pan et al., 1996), topography (Gao et al., 2013), drought (Pei et al., 2013a), $\mathrm{CO}_{2}$ concentration (Mu et al., 2008), and so on, their effects on NPP were less climatic factors on carbon storage of vegetation (Sui et al., 2013; Gao et al., 2013).

\section{NPP dynamics and associated urbanization and LULCC}

Urbanization and subsequent LULC driven by human activities are important factors affecting vegetation dynamics, particularly in highly urbanized areas that are characterized by extremely fragile ecosystems (Wu and Wu, 2018; Zhang et al., 2014; Liu et al., 2018). In this study, NPP exhibited spatial heterogeneity across the whole area under study and decreased in the five regions from 2001 to 2013. Similarity, previous studies found that vegetation was degraded at different levels in Guangzhou in recent decades ( $\mathrm{Fu}$ et al., 2013; $\mathrm{Hu}$ et al., 2009; $\mathrm{Wu}$ and $\mathrm{Wu}, 2018$ ). In our study, a significant reduction in NPP was concentrated in the inner suburbs (southern, eastern, and northern regions; Fig. 5), this was mostly because that the amount of urban sprawl increased gradually from center to the periphery from 2001 to 2013 (Wu et al., 2016), and urbanization "hot spots" have moved from the center to the suburbs, resulting in a substantial reduction in vegetation areas and vegetation carbon fixation. Following intense urban development, ecological degradation slows and new urban ecosystems develop (Peng et al., 2016), which always leads to large losses in NPP. Moreover, the significant increase in RII in the inner suburbs implied that vegetation productivity in these areas was still subjected to disturbance by human activities. Most studies have demonstrated that the urban fringe is gradually emerging as the most human-disturbed area and this phenomenon has been observed in most urban areas during urbanization (Xu et al., 2007; Wu et al., 2014; Wu and Wu, 2018). Conversely, increased NPP and smaller RII values were widely distributed in the outer suburbs (northeastern region), which are dominated by mountains and hills with higher elevations, and low population density combined with conservation efforts that have effectively reduced the impacts of humans on vegetation activity. This phenomenon has also been confirmed by other studies (Peng et al., 2016; Hu et al., 2009).

Prior research has verified that different urbanization stages, finance aggregation, and population growth may also be important factors affecting NPP variability (Peng et al., 2016; Lu et al., 2010). Substantial environmental change occurs under increased demand by city dwellers for green space and corresponding ecosystem services. Thus, maintaining green spaces and adaptive urban planning could have benefits for the urban ecosystem and a favorable impact on vegetation productivity. However, it should be noted that growing human activity and urban sprawl are still a serious threat to vegetation NPP accumulation, and more plausible adaptation strategies should be 
employed to cope with the conflict between urban development and ecosystem carbon balance.

\section{Dominant driving forces of NPP variability}

Over the 13-year study period, temperature and solar radiation were generally favorable for vegetation growth, whereas human activities had a negative impact. As shown by the absolute values of the contributions made by climate and LULCC, the influence of LULCC on interannual NPP variability in most parts of the area under study was always greater than climate. Notably, negative impacts of LULCC on NPP were most significant in the inner suburbs due to the conversion from vegetated to nonvegetated land, especially from cropland to new urban areas. This finding was in agreement with several studies (Pei et al., 2013b; Fu et al., 2013; Wu et al., 2014; Yang et al., 2015; Liu et al., 2018). A considerable proportion NPP change was undeniably dominated by climate factors in some croplands and wooded areas (e.g. the northeastern region; Fig. 8), where LULCC actually caused an increase in NPP. This was closely related to regional land cover types, population and economic conditions, terrain, conservation policies, and so on. In addition to the roles of regional population, economic conditions, and terrain, the effects of protection policies must be acknowledged. For example, the Land Use Master Plan of Guangzhou (1997-2010) effectively prevented excessive losses of agricultural land in this region. The Urban Master Development Strategic Plan of Guangzhou (2010-2020) defined Conghua and Zengcheng (the two districts are mainly in northeastern region) as eco-agricultural and eco-tourism zones, which further promoted the protection of agricultural and forested lands in the northeastern region and contributed to forest carbon accumulation. This limited the NPP reduction caused by climate change.

RII is an effective index for evaluating the effects of LULCC alone, independent of climate change, on NPP. In this study, we used RII to further assess the effects of climate change and LULCC on NPP. The fit curve of frequency by pixels of RII indicated that RII values were mostly positive (Fig. 9) in five regions, ranging from 50$90 \%$, indicating that human activity had a negative effect on vegetation productivity and NPP.

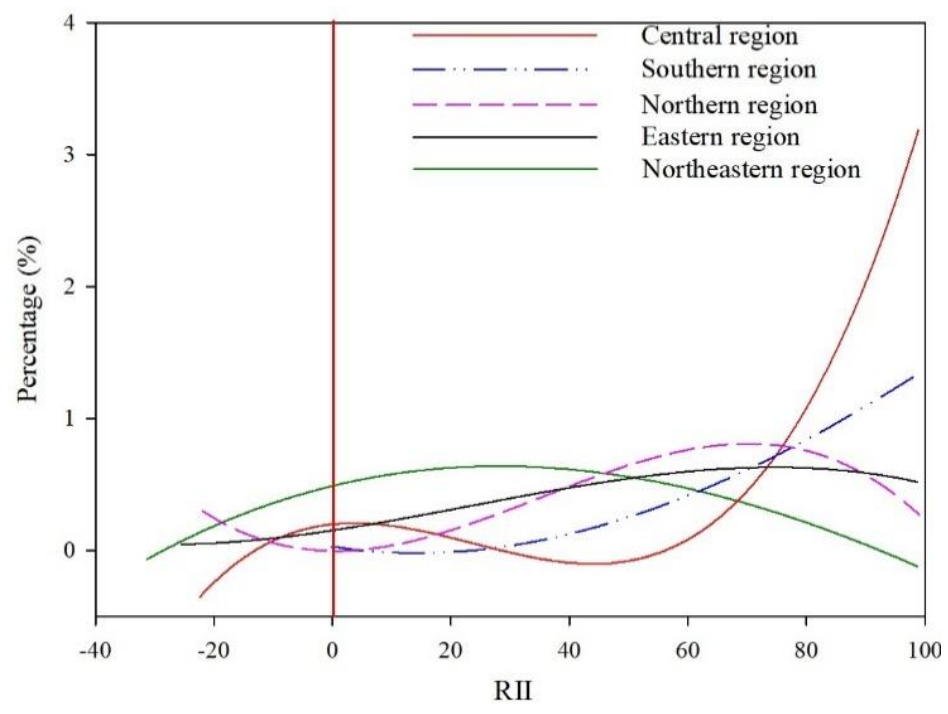

Figure 9. Fit curve of frequency by pixels of RII in five regions 
In addition, mean RII values were greater than 50\% in all regions and about $77.3 \%$ of those pixels were concentrated in the inner suburbs, suggesting that NPP variability was most affected by human activities. These findings were consistent with our results based on the method of $\mathrm{Wu}$ et al. (2014). Especially, about $17.12 \%$ pixels in RII were less than 0 in northeastern region, which was benefited by the protection policies of agriculture and forested lands. Nonetheless, it is worth noting that the increase in RII over the five regions (Table 4) meant that human impacts on NPP through LULCC also increased, and vegetation productivity was affected by human disturbance, especially in inner suburbs. Although the creation and protection of urban green spaces, forests, and wetlands contributed to the increase in NPP, the effects of some protection projects were less than satisfactory. The effectiveness of restoration projects and urban and industrial land use plans should be adjusted to balance environmental conservation and economic development, and more plausible adaptation strategies should be applied to cope with climate change.

\section{Conclusions}

NPP is one of the most significant factors characterizing ecosystem structure and function, and can be used to describe the spatiotemporal pattern of urban carbon storage and its driving mechanisms. The current study estimated NPP change in Guangzhou and its five regions from 2001 to 2013 and examined the effects of driving forces on NPP variability in a spatially explicit way. Nonlinear NPP trends indicated that NPP decreased across the study area and most significantly in the inner suburbs (southern, eastern, and northern regions) due to rapid urbanization and human interference, while a slight increase of NPP was concentrated in the western part of the northeastern region. Solar radiation and temperature strongly influenced NPP increases, while precipitation was a limiting factor. NPP reductions were correlated with urban sprawl combined with land conversions from vegetated areas to impervious surface, especially cropland to built-up land. More than $91.0 \%$ of pixels had positive RII values, implying that LULCC played a negative role in NPP accumulation.

Comparatively, there were significant differences in the effects of climate change and LULCC on NPP. More than $67.2 \%$ of pixels exhibited NPP trends that were dominated by LULCC, and absolute average RII values further confirmed that LULCC had a greater impact than climate change on NPP. The interacting effects of climate change and LULCC led to slight NPP variability. In the northeastern region, about $38.1 \%$ of pixel NPP trends were dominated by climate change, but it cannot be ignored that the influence of human activities on vegetation productivity is still increasing and prolonged efforts will be needed to protect and expand environmental resources in this region. The above results revealed that LULCC due to urban expansion, rather than climate variability, was the main cause for regional NPP reductions in Guangzhou.

NPP variability can also be an indicator of urban development intensity and will provide further insights into terrestrial carbon change resulting from urbanization. In particular, the obvious spatial heterogeneity in the effects of LULCC and climate change on NPP change can provide valuable decision support information for ecological conservation and management in this region. Moreover, it is noteworthy that with the increase in impervious surface and decrease in vegetation cover resulting from human activities, the urban heat island effect will likely be intensified and the decline of cultivated land and forest will threaten food security and ecosystem function. Future 
work should aim to improve data resolution and delve further into the mechanisms coupling land use change, climate change and the carbon cycle for a long time. And further work is also needed to identify the mechanisms of cropland NPP and food security to urban expansion.

Acknowledgements. This study was supported by the Natural Science Foundation of Guangdong Province of China (2018A030310069) and the National Natural Science Foundation of China (61806059, 41671430).

\section{REFERENCES}

[1] Ahlström, A., Miller, P. A., Smith, B. (2012): Too early to infer a global NPP decline since 2000. - Geophysical Research Letters 39(15): 15403.

[2] Benali, A., Carvalho, A. C., Nunes, J. P., Carvalhais, N., Santos, A. (2012): Estimating air surface temperature in Portugal using MODIS LST data. - Remote Sensing of Environment 124: 108-121.

[3] Buyantuyev, A., Wu, J. G. (2012): Urbanization diversifies land surface phenology in arid environments: Interactions among vegetation, climatic variation, and land use pattern in the Phoenix metropolitan region, USA. - Landscape and Urban Planning 105(1-2): 149-159.

[4] Chao, Z. H., Zhang, P. D., Wang, X. F. (2018): Impacts of urbanization on the net primary productivity and cultivated land change in Shandong Province, China. Journal of the Indian Society of Remote Sensing 46(2): 1-11.

[5] Chen, T., Huang, Q. H., Liu, M., Li, M. C., Qu, L. A., Deng, S. L., Chen, D. (2017): Decreasing net primary productivity in response to urbanization in Liaoning Province, China. - Sustainability 9(2): 162.

[6] Dekker, S. C., Rietkerk, M., Bierkens Arc, F. P. (2007): Coupling microscale vegetation, soil water and macroscale vegetation, precipitation feedbacks in semiarid ecosystems. - Global Change Biology 13(3): 671-678.

[7] Eisfelder, C., Klein, I., Niklaus, M., Kuenzer, C. (2014): Net primary productivity in Kazakhstan, its spatio-temporal patterns and relation to meteorological variables. Journal of Arid Environments 103(8): 17-30.

[8] Fang, X., Zhang, C., Wang, Q., Chen, X., Ding, J. L., Karamage, F. (2017): Isolating and quantifying the effects of climate and CO2 changes (1980-2014) on the net primary productivity in arid and semiarid China. - Forests 8(3): 1-19.

[9] Field, C. B., Behrenfeld, M. J., Randerson, J. T., Falkowski, P. (1998): Primary production of the biosphere: integrating terrestrial and oceanic components. - Science 281(5374): 237-40.

[10] Fu, G., Shen, Z. X., Zhang, X. L., Shi, P. L., Zhang, Y. J., Wu, J. S. (2011): Estimating air temperature of an alpine meadow on the Northern Tibetan Plateau using MODIS land surface temperature. - Acta Ecologica Sinica 31(1): 8-13.

[11] Fu, Y. C., Lu, X. Y., Zhao, Y. L., Zeng, X. T., Xia, L. (2013): Assessment impacts of weather and land use/land cover (LULC) change on urban vegetation net primary productivity (NPP) a case study in Guangzhou, China. - Remote Sensing 5(8): 41254144.

[12] Gao, Q. Z., Wang, Y. F., Li, Y., Guo, Y. Q., Ganjurjav, Qin, X., Jiang, C. W., Wang, B. (2013): Effects of topography and human activity on the net primary productivity (NPP) of alpine grassland in northern Tibet from 1981 to 2004. - International Journal of Remote Sensing 34(6): 2057-2069.

[13] Gao, Z. Q., Liu, J. Y. (2008): A comparative study of Chinese vegetation net productivity. - Chinese Science Bulletin 53(3): 317-326. 
[14] Gong, W., Wang, L. C., Lin, A. W., Zhang, M. (2012): Evaluating the monthly and interannual variation of net primary production in response to climate in Wuhan during 2001 to 2010. - Geosciences Journal 16(3): 347-355.

[15] Grimm, N. B., Faeth, S. H., Golubiewski, N. E., Redman, C. L., Wu, J., Bai, X., Briggs, J. M. (2008): Global change and the ecology of cities. - Science 319(5864): 756-760.

[16] Gu, F. X., Zhang YD, Huang, M., Guo, Tao, B., Liu, Z. J., Hao, M., Guo, R. (2017): Climate-driven uncertainties in modeling terrestrial ecosystem net primary productivity in China. - Agricultural and Forest Meteorology 246: 123-132.

[17] Hou, G. L., Li, J. Y., Zhang, Y. G. (1993): China Agricultural Climate Resources. China Renmin University Press, Beijing (in Chinese).

[18] Hu, Y. H., Jia, G. S., Guo, H. D. (2009): Linking primary production, climate and land use along an urban-wildland transect: a satellite view. - Environmental Research Letters 4(4): 044009.

[19] Hua, X. B. (2009): Quantifying the human appropriation of net primary production and analysis of its multi-year changes in Guangdong. - Master Thesis, Sun Yat-sen University (in Chinese).

[20] Hutyra, L. R., Yoon, B., Hepinstall-Cymerman, J., Alberti, M. (2011): Carbon consequences of land cover change and expansion of urban lands: A case study in the Seattle metropolitan region. - Landscape and Urban Planning 103(1): 83-93.

[21] Imhoff, M. L., Tucker, C. J., Lawrence, W. T., Stutzer, D. C. (2000): The use of multisource satellite and geospatial data to study the effect of urbanization on primary productivity in the united states. - IEEE Transactions on Geoscience and Remote Sensing 38(6): 2549-2556.

[22] Jiang, C., Wu, Z. F. (2015): Impacts of urbanization on net primary productivity in the Pearl River Delta, China. - International Journal of Plant Production 9(4): 581-598.

[23] Kendall, M. G. (1975): Rank Correlation Methods. - Griffin, London, UK.

[24] Liang, L., Zhou, S. H., Qin, Z. H., He, K. X., Chen, C., Luo, Y. X., Zhou, X. D. (2014): Drought change trend using MODIS TVDI and its relationship with climate factors in China from 2001 to 2010. - Journal of Integrative Agriculture 13(7): 1501-1508.

[25] Liu, H. Y., Mi, Z. R., Lin, L., Wang, Y. H., Zhang, Z. H., Zhang, F. W., Wang, H., Liu, L. L. (2018): Shifting plant species composition in response to climate change stabilizes grassland primary production. - Proceedings of the National Academy of Sciences 115(16): 4051-4056.

[26] Liu, S. S., Du, W., Su, H., Wang, S. Q., Guan, Q. F. (2018): Quantifying impacts of land-use/cover change on urban vegetation gross primary production: a case study of Wuhan, China. - Sustainability 10(3): 714.

[27] Lu, D. S., Xu, X. F., Tian, H. Q., Moran, E., Zhao, M. S., Running, S. (2010): The effects of urbanization on net primary productivity in Southeastern China. Environmental Management 46(3): 404-410.

[28] Mohamed, M. A. A., Babiker, I. S., Chen, Z. M., Ikeda, K. Ohta, K., Kato, K. (2004): The role of climate variability in the inter-annual variation of terrestrial net primary production (NPP). - Science of the Total Environment 332(1-3): 123-137.

[29] Mu, Q. Z., Zhao, M. S., Running, S. W., Liu, M. L., Tian, H. Q. (2008): Contribution of increasing $\mathrm{CO} 2$ and climate change to the carbon cycle in China's ecosystems. Journal of Geophysical Research Biogeosciences 113(1): 1-15.

[30] Neeti, N., Eastman, J. R. (2011): A contextual Mann-Kendall approach for the assessment of trend significance in image time series. - Transactions in GIS 15(5): 599-611.

[31] Nemani, R. R., Keeling, C. D., Hashimoto, H., Jolly, W. M. Piper, S. C., Tucker, C. J., Myneni, R. B., Running, S. W. (2003): Climate-driven increases in global terrestrial net primary production from 1982 to 1999. - Science 300(5625): 1560-3. 
[32] Ni, J. (2003): Net primary productivity in forests of China: scaling-up of national inventory data and comparison with model predictions. - Forest Ecology and Management 176(1-3): 485-495.

[33] Pan, Y., Mcguire, A. D., Kicklighter, D. W., Melillo, J. (1996): The importance of climate and soils for estimates of net primary production: a sensitivity analysis with the terrestrial ecosystem model. - Global Change Biology 2(1): 5-23.

[34] Pei, F. S., Li, X., Liu, X. P., Lao, C. H. (2013a): Assessing the impacts of droughts on net primary productivity in China. - Journal of Environmental Management 114(2): 362-371.

[35] Pei, F. S., Li, X., Liu, X. P., Wang, S. J., He, Z. J. (2013b): Assessing the differences in net primary productivity between pre- and post-urban land development in China. Agricultural and Forest Meteorology 171-172(3): 174-186.

[36] Pei, F. S., Li, X., Liu, X. P., Lao, C. H., Xia, G. R. (2015): Exploring the response of net primary productivity variations to urban expansion and climate change: A scenario analysis for Guangdong Province in China. - Journal of Environmental Management 150(150C): 92-102.

[37] Peng, J., Shen, H., Wu, W., Liu, Y., Wang, Y. (2016): Net primary productivity (NPP) dynamics and associated urbanization driving forces in metropolitan areas: a case study in Beijing City, China. - Landscape Ecology 31(5): 1077-1092.

[38] Piao, S., Fang, J. Y., Zhou, L. M., Zhu, B., Tan, K., Tao, S. (2005): Changes in vegetation net primary productivity from 1982 to 1999 in China. - Global Biogeochemical Cycles 19(2): 1605-1622.

[39] Piao, S. L., Fang, J. Y., Chen, A. P. (2003): Seasonal dynamics of terrestrial net primary production in response to climate changes in China. - Acta Botanica Sinica 45(3): 269-275.

[40] Piao, S. L., Fang, J. Y., Ciais, P., Peylin, P., Huang, Y., Sitch, S., Wang, T. (2009): The carbon balance of terrestrial ecosystems in China. - Nature 458(7241): 1009-1013.

[41] Potter, C. S., Randerson, J. T., Field, C. B., Matson, P. A., Vitousek, P. M., Mooney, H. A., Klooster, S. A. (1993): Terrestrial ecosystem production: A process model based on global satellite and surface data. - Global Biogeochemical Cycles 7(4): 811-841.

[42] Prince, S. D. (1991): A model of regional primary production for use with coarse resolution satellite data. - International Journal of Remote Sensing 12(6): 1313-1330.

[43] Sui, X. H., Zhou, G. S., Zhuang, Q. L. (2013): Sensitivity of carbon budget to historical climate variability and atmospheric $\mathrm{CO} 2$ concentration in temperate grassland ecosystems in China. - Climatic Change 117(1-2): 259-272.

[44] Tucker, C. J., Newcomb, W. W., Dregne, H. E. (1994): AVHRR data sets for determination of desert spatial extent. - International Journal of Remote Sensing 15(17): 3547-3565.

[45] Vancutsem, C., Ceccato, P., Dinku, T., Connor, S. J. (2010): Evaluation of MODIS land surface temperature data to estimate air temperature in different ecosystems over Africa. - Remote Sensing of Environment 114(2): 449-465.

[46] Verburg, P. H., Soepboer, W., Veldkamp, A., Limpiada, R., Espaldon, V., Mastura, S. S. A. (2002): Modeling the spatial dynamics of regional land use: the CLUE-S model. Environmental Management 30(3): 391-405.

[47] Wang, C. Z., Guo, H. D., Zhang, L., Liu, S. Y., Qiu, Y. B., Sun, Z. C. (2015a): Assessing phenological change and climatic control of alpine grasslands in the Tibetan Plateau with MODIS time series. - International Journal of Biometeorology 59(1): 112.

[48] Wang, H., Li, X. B., Long, H. L., Zhu, W. Q. (2009): A study of the seasonal dynamics of grassland growth rates in Inner Mongolia based on AVHRR data and a light-use efficiency model. - International Journal of Remote Sensing 30(14): 3799-3815. 
[49] Wang, J., Price, K. P., Rich, P. M. (2001): Spatial patterns of NDVI in response to precipitation and temperature in the central Great Plains. - International Journal of Remote Sensing 22(18): 3827-3844.

[50] Wang, J., Wang, K. L., Zhang, M. Y., Zhang, C. H. (2015b): Impacts of climate change and human activities on vegetation cover in hilly southern China. - Ecological Engineering 81: 451-461.

[51] Wang, L. C., Gong, W., Ma, Y. Y., Zhang, M. (2013): Modeling regional vegetation NPP variations and their relationships with climatic parameters in Wuhan, China. Earth Interactions 17(4): 1-20.

[52] Wu, S. H., Zhou, S. L., Chen, D. X., Wei, Z. Q., Dai, L., Li, X. G. (2014): Determining the contributions of urbanisation and climate change to NPP variations over the last decade in the Yangtze River Delta, China. - Science of the Total Environment 472: 397-406.

[53] Wu, Y. Y., Li, S. Y., Yu, S. X. (2016): Monitoring urban expansion and its effects on land use and land cover changes in Guangzhou city, China. - Environmental Monitoring and Assessment 188(1): 54.

[54] Wu, Y. Y., Wu, Z. F. (2018): Quantitative assessment of human-induced impacts based on net primary productivity in Guangzhou, China. - Environmental Science and Pollution Research 25(12): 11384-11399.

[55] Xu, C., Liu, M., An, S., Chen, J. M., Yan, P. (2007): Assessing the impact of urbanization on regional net primary productivity in Jiangyin County, China. - Journal of Environmental Management 85(3): 597-606.

[56] Xu, D. Y., Li, C. L., Zhuang, D. F., Pan, J. J. (2011): Assessment of the relative role of climate change and human activities in desertification: a review. - Journal of Geographical Sciences 21(5): 926-936.

[57] Yan, H., Zhan, J., Wu, F., Yang, H. (2016): Effects of climate change and LUCC on terrestrial biomass in the Lower Heihe River Basin during 2001-2010. - Energies 9(4): 9-14.

[58] Yang, L. Y., Zhang, L. B., Li, Y., Wu, S. T. (2015): Water-related ecosystem services provided by urban green space: A case study in Yixing city (China). - Landscape and Urban Planning 136: 40-51.

[59] Zhang, F. Y., Pu, L. J., Huang, Q. (2015): Quantitative assessment of the human appropriation of net primary production (HANPP) in the coastal areas of Jiangsu, China. - Sustainability 7(12): 15857-15870.

[60] Zhang, J. H., Hu, Y. L., Xiao, X. M., Chen, P. S., Han, S. J., Song, G. Z., Yu, G. R. (2009): Satellite-based estimation of evapotranspiration of an old-growth temperate mixed forest. - Agricultural and Forest Meteorology 149(6-7): 976-984.

[61] Zhang, W. T., Huang, B., Luo, D. (2014): Effects of land use and transportation on carbon sources and carbon sinks: a case study in Shenzhen, China. - Landscape and Urban Planning 122(2): 175-185.

[62] Zhang, Y., Zhang, C. B., Wang, Z. Q., Chen, Y. Z., Gang, C. C., An, R., Li, J. H. (2016): Vegetation dynamics and its driving forces from climate change and human activities in the Three-River Source Region, China from 1982 to 2012. - Science of the Total Environment 563-564: 210-220.

[63] Zhang, Y. L., Song, C. H., Zhang, K. R., Cheng, X. L., Zhang, Q. F. (2014): Spatialtemporal variability of terrestrial vegetation productivity in the Yangtze River Basin during 2000-2009. - Journal of Plant Ecology 7(1): 10-23.

[64] Zhao, M., Running, S. W. (2010): Drought-induced reduction in global terrestrial net primary production from 2000 through 2009. - Science 329(5994): 940-943.

[65] Zhao, T. T., Brown, D. G., Fang, H. L., Theobald, D. M. Liu, T., Zhang, T. (2012): Vegetation productivity consequences of human settlement growth in the eastern United States. - Landscape Ecology 27(8): 1149-1165. 
[66] Zhu, W. Q., Pan, Y. Z., He, H., Yu, D. Y., Hu, H. B. (2006): Simulation of maximum light use efficiency for some typical vegetation types in China. - Chinese Science Bulletin 51(4): 457-463.

[67] Zhu, W. Q., Pan, Y. Z., Yang, X. Q., Song, G. B. (2007a): Comprehensive analysis of the impact of climatic changes on Chinese terrestrial net primary productivity. Chinese Science Bulletin 52(23): 3253-3260.

[68] Zhu, W. Q., Pan, Y. Z., Zhang, J. S. (2007b): Estimation of net primary productivity of Chinese terrestrial vegetation based on remote sensing. - Chinese Journal of Plant Ecology 31(3): 413-424. 